Preprint, the final version, of the article that has been transferred to the journal's production team.

To cite this article: Federica Natalia Rosati, Luisa Moretto \& Jacques Teller (2020) An incremental approach to service co-production: unfolding the co-evolution of the built environment and water and sanitation infrastructures, International Journal of Urban Sustainable Development, DOI: 10.1080/19463138.2020.1818085

\title{
An incremental approach to service co-production: unfolding the co- evolution of the built environment and water and sanitation infrastructures
}

The literature is increasingly approaching the participation of households in the delivery of urban services through the lens of co-production. However, there has been no indepth exploration of the relationship between incremental changes in the urban fabric (urban typologies and morphologies) and the forms of adaptations of co-produced water and sanitation services. The paper draws on three planned neighbourhoods in Hanoi to examine these incremental changes by considering the transformation of the neighbourhood at different scales and the consequent evolution of the sociotechnical arrangements for the delivery of water and sanitation services. By exploring forms of reconfiguration of the built environment and embedded water infrastructures, the paper outlines the possibility of an alternate reading of service co-production initiatives as incremental spatial practices, with an emphasis on the role of technology in allowing transformation processes.

Keywords: water and sanitation services, co-production, urban transformation, incremental infrastructures, Hanoi

\section{Introduction}

The participation of communities in the processes of formation and consolidation of urban settlements and related infrastructure is becoming increasingly important in fastgrowing cities in the Global South. "Incremental", "tactical", "handmade" world cities are rapidly growing outside and beyond planning processes, challenging the ability of national and local governments to keep up with the provision of integrated services to urban dwellers. The concept of incrementalism has entered urban studies, referring to the intensive multiplicity that characterises the process of city making (Deleuze and 
Guattari 1987). In this view, the city is the result of a step-by-step process that leads to consolidation over time through new spatial additions and reconfigurations that combine social and material activities (McFarlane 2011).

While many urban buildings, especially in the global South, are autoconstructed and continually adapted - even architecturally designed buildings are constantly being tinkered with. This produces gradual but distinctive changes in their layout, skin and appearance. Very often, the issues raised by this continual repair and adaptation of buildings are actually completely ignored in the original design process. (Graham and Thrift 2007, p. 17)

The reconfiguration of infrastructure networks occurs not only over the long term, but also through small changes and variations, which, combined, cause their global transformation. Offner (1993) suggests that incremental networks are characterised by a paradoxical change in continuity, i.e. networks are built from pre-existing networks and develop new configurations in a relationship of complementarity or competition. In this sense, the sociotechnical process of co-production of water and sanitation services (WSS) acts as an incremental learning process through which urban dwellers participate in making their cities, shaping their organisational limits and conditions of possibility (McFarlane 2011; Silver 2014).

In Hanoi, Vietnam's capital city, investments in large-scale infrastructures contribute to extending the access to centralised water and sanitation networks. Still the limitations of centralised water networks (i.e. irregular and unsafe drinking water provision, insufficient wastewater collection and treatment) along with processes of territorial reconfiguration (i.e. densification of built-up areas, rural-urban reconversion) require citizens to engage in co-production of water and sanitation services, leading to pragmatic reconfigurations of technical devices and infrastructure systems (Button 2017). This paper analyses the coevolution of the built environment and embedded water and sanitation infrastructures. In this perspective, service co-production acts as an incremental practice. The paper explores the following questions. How and why did planned built environments become sites of service co-production? What was the role of incremental adaptations of water and sanitation infrastructures in the co-production of services?

The article firstly discusses incrementalism as a theoretical framework to understand how, through co-production, Hanoi dwellers can achieve improved water supply and sanitation by means of hybrid infrastructures and incremental sociotechnical 
development. It uses three case studies of planned neighbourhoods to analyse how urban dwellers engage with existing spatial conditions, reconfigure their urban space and seek to adjust and maintain the circulation of water on a very local scale to respond to increasing density. It concludes by outlining some theoretical considerations resulting from examining the development of water and sanitation infrastructure and the technical devices employed in incremental development by stressing the place-based nature of coproduction and, at the same time, co-production's path dependency on the dynamics of urban transformations.

\section{Co-production as incremental spatial practice}

For much of the past hundred years, governments have been experimenting with various models, policies and strategies to deliver public services to an increasing number of urban dwellers. After a period dominated by centralization, liberalization and privatization, service co-production has aroused interest both in the Global North and the Global South. A broad literature, mostly on public administration, has conceptualised and delimited the boundaries of citizen-state engagement in service coproduction (Brudney and England 1983; Joshi and Moore 2004; Moretto and Ranzato 2017; Nabatchi et al. 2017). Most research addresses the motivations behind service coproduction (why do service users co-produce), its institutional setting (how do users and providers interact) and its benefits. Within Urban South studies, service co-production is often seen as a way to overcome the dichotomy between formal and informal approaches to urban planning and service delivery (Faldi et al. 2019; Misra 2014). The literature refers to the collaborative dimension of service co-production and its longterm benefits. The interest in co-production of public services is underpinned by the view that the engagement of users in some or all the phases of the service cycle may bring double benefits. For some, co-production constitutes a service delivery model that may improve service efficiency and accountability by making better use of the available resources while increasing trust among the actors involved. Indeed, state and citizens have different but complementary forms of knowledge, which together can contribute to improving service outcomes (Ostrom 1996; Watson 2014). For others, the move toward co-production as public governance and policy framing tool is a way of addressing institutional deficits by favouring the reconfiguration of state-society relationships through the rise of new democratic institutions (Mitlin, 2008). By contrast some authors raise concerns about co-production initiatives as forms of co-optation, as vehicles for the 
institutionalisation of inequalities (Cornwall 2004; Jaglin 2002) and as drivers of sociospatial fragmentation (Moretto et al. 2018; Cabrera 2015).

Literature on socio-technical systems generally conceives service co-production as a decentralized, hybrid form of service delivery developed to bridge the gaps left by poor or absent centralized networks. In this literature, there are references to the adaptability of co-produced systems, related to the local capacity mobilized for dealing with resources and technologies. However, there are major challenges in guaranteeing sustainable management of the system, maintaining service equity and efficiency and ensuring water and environmental standards (Faldi et al. 2019). In spite of a still blurred definition and controversies over its benefits, co-production is generally mobilized as a policy tool for integration into urban planning or public services delivery schemes to improve service quality while promoting more horizontal governance forms (Joshi and Moore, 2004; Mitlin, 2008; Ostrom, 1996).

The definition for this paper comes from Joshi and Moore (2004), which defines institutionalised service co-production as "the provision of public services (broadly defined to include regulation) through a regular long-term relationship between state agencies and organized groups of citizens where both make substantial resource contributions" (p. 31). This framework is appropriate for our study, since it recognises the key role organised service users play in the service delivery process, within complex policy arrangements over a wide timeframe, in which state-society synergistic relationships are being continuously renegotiated. Moreover, we consider a number of intermediaries, such as community groups, volunteering associations, NGOs and private companies that might endorse different roles as co-producers and co-managers, thus contributing to negotiating the boundaries between state and society (Bovaird 2007).

However, in this paper we step back from the more traditional understanding of service co-production and we approach it from a descriptive rather than a normative perspective. In other words, we do not focus on the collaborative dimension of coproduction practices; nor do we evaluate their benefits in terms of quality of services. The focus is rather on understanding how service co-production develops. This implies exploring different types of co-production initiatives and their evolution over time. In particular, we focus on the co-production of WSS. As supply forms are part of the built environment, it is relevant to include spatial considerations in the observation of coproduced water and sanitation services (Faldi et al. 2019; Moretto et al. 2018). The way co-production is influenced by and influences the reconfiguration of the built environment and how it evolves over time, in terms of space, technology and involved social structures, has not yet received extensive exploration. In this paper, service co- 
production is understood as an incremental practice, namely a process in which hybrid modalities of service provision, involving state actors, service users and a wide range of intermediaries, are interacting in an evolving socio-political, technical and territorial context (Ahlers et al. 2014; Faldi et al. 2019; Joshi and Moore 2004).

Reading service co-production as an incremental spatial practice, as opposed to a policy or a static service delivery model, helps us to understand its origin, evolution and role in the transformation of Global South cities. Three main aspects allow us to read coproduction as incremental spatial practice. The evolutionary dimension of WSS coproduction is primarily linked with the role of the state and its changing relationship with society. Governance drivers, as changes in the political environment at the national or local scale, might trigger a decline in state provision (institutional deficit) and therefore engage citizens in co-production. Logistic or technical drivers, such as distance to the urban core, might also explain why communities, disconnected from networked infrastructures, get involved in service delivery (Joshi and Moore 2004). Co-production might evolve as a substitutive practice (i.e. government retiring from being service provider) or as an additive practice (i.e. institutionalisation of self-help practices or conventional service provision models supported by users) (Bovaird and Loeffler 2012). Consequently, the relationships between actors involved in service co-production and their long-term goals are constantly under negotiation.

Moreover, as water and sewerage infrastructures (tanks, pumps, pipes) are embedded in the physical boundaries of the built environment, there is a relationship between this the form and structure of this built environment and the territorial boundaries of co-produced practices (Habraken and Teicher 1998; Ostrom 1990). Dwellers may operate in different ways with respect to their built environment at a local scale (Habraken and Teicher 1998; Moretto et al. 2018; Silver 2014). Local factors, such as available resources or dwelling typologies, shape the evolution of the different coproduction options, along path-dependency trajectories (Faldi et al. 2019; Monstadt and Schramm 2015). Changes in territorial configuration (form and control of the built environment) might require adaptation of some water infrastructures. This in turn may contribute to the evolution of co-production practices (Habraken and Teicher 1998; Offner 1993). Echoing Cornwall (2004), co-production can take the form of "invited space" (i.e. government supporting incremental transformations of the built environment) or "popular space" (i.e. bottom-up initiatives occurring outside regulatory frameworks). However, the "boundaries between 'invited' and 'popular' spaces are mutable, rather than fixed. 'Popular spaces' can become institutionalised, with statutory backing, and 'invited spaces' may become sites for the articulation of dissent, as well as 
for collaboration and compromise" (Cornwall 2004, p. 2). The evolution of the built environment may influence co-production that keeps "in-the-making, undergoing constant adjustment and intervention, and in a permanent state of flux" (Silver 2014, p. 788).

Finally, the evolution of WSS co-production is also linked with the unfinished nature of infrastructure networks (Button 2017; Faldi et al. 2019; Zérah 2000). The adaptability of WSS infrastructures plays an important role in the sociotechnical and spatial reconfiguration of co-produced water and sanitation services. The incremental development of infrastructures can take different shapes. First, it can act as an upgrade of the technical portfolio used in co-production (Moretto et al. 2018); second, it can act as a multiplication of supply systems and related technical devices used in co-production (Button 2017); third, it can act as an extension of co-produced services to include new dwellers (Cabrera 2015). Finally, co-production might evolve to cover the gaps between conventional and networked infrastructures, revealing a stop-gap nature (Jaglin 2002; Zérah 2000).

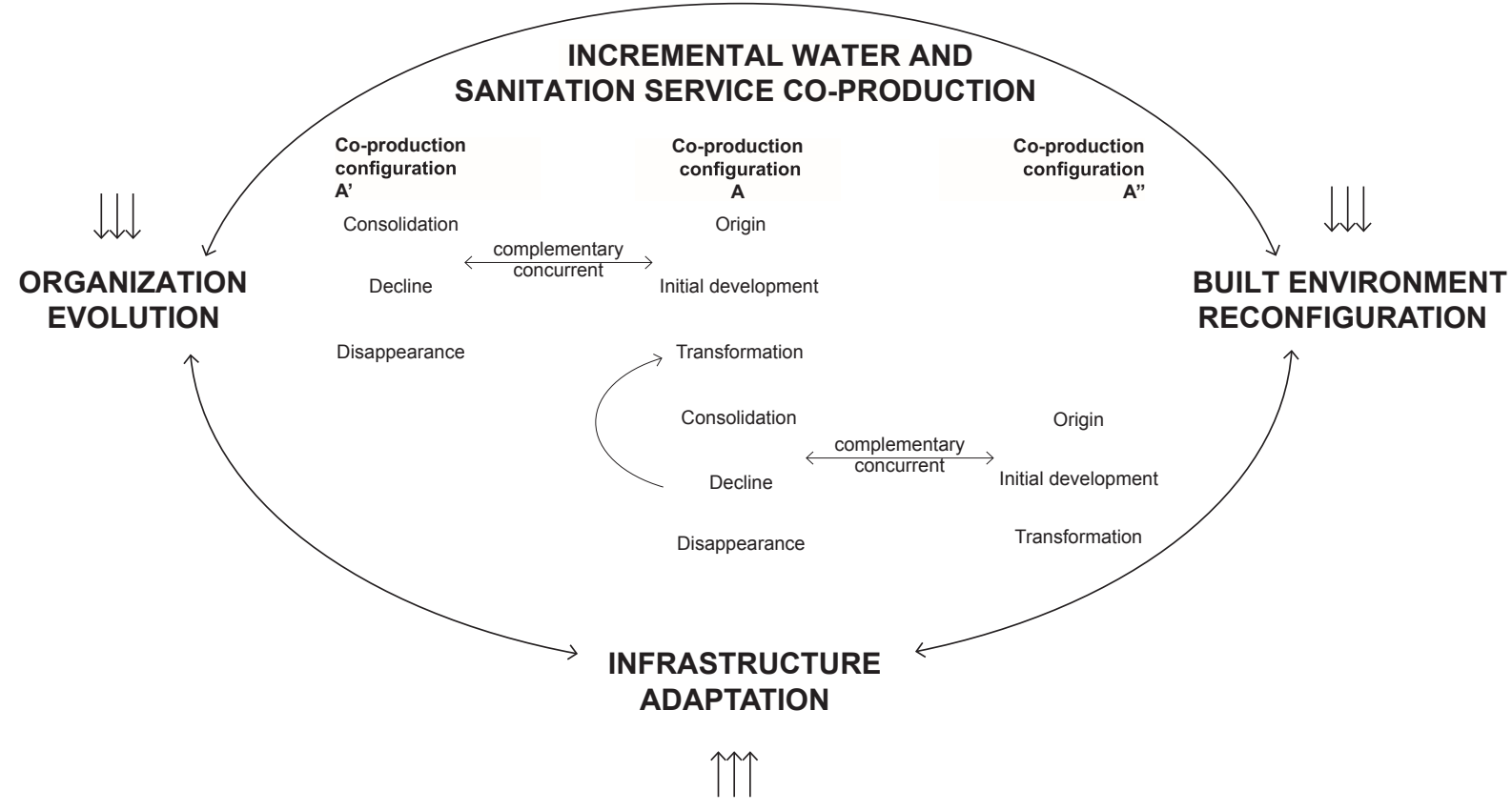

Figure 1. Framework for analysing the evolution of co-production of water and sanitation services. Developed by the authors based on Offner (1993).

Grounded in the idea that the co-production of water and sanitation services has a path-dependent nature, this paper draws attention to the relationship between the 
evolution of co-produced practices and the processes of consolidation and transformation of human settlements. It does so by looking at the incremental nature of the built environment and the role of incrementalism in sustaining urban livelihoods through processes of maintenance, upgrade and transformation of WSS infrastructures (Button 2017; Graham and Thrift 2007; Offner 1993; Silver 2014).

\section{Between popular and invited development: Hanoi's incremental growth}

The second largest city in Vietnam, Hanoi, is growing rapidly and occupies an area of $3.300 \mathrm{~km}^{2}$ in the Red River Delta (Labbé and Musil 2014). According to several authors, urbanisation processes in Hanoi are the outcomes of socialist approaches and market mechanisms that characterise the fluid and contrasting nature of state-society relationships in space production logics (Geertman 2003; McGee 2009; Tran 2015). On the one hand, there are large-scale urban plans, representing globally circulating visions of modernity and characterised by connectedness to centralised infrastructure networks (Schramm 2016b). The plans drawn by French colonials supporting the image of a sanitary city, the interventions drawn with technical and economic support from the former Soviet Union and the current masterplan that promotes the image of neoliberal city development (Aimini 2013) fall into this category. On the other hand, and in contrast to these planned forms of city development, urbanism in Hanoi is also produced on the local scale, determined by site-specific social and spatial instances, in a pragmatic and incremental way (Geertman 2007; Kerkvliet 2001; Koh 2006). A number of policies adopted from the 1980s, in contrast with the progressive retreat of the government in the provision and maintenance of the housing stock, de facto invited and institutionalised unplanned and popular urban growth (Cerise 2009; Geertman and Kim 2019).

The tensions between planning models and material improvisations that arise in the city's incremental development emerge at different scales and determine the way infrastructure is produced and reconfigured and the ways that water and sanitation services are currently delivered to urban dwellers (Schramm 2014). While expanding and transforming to sustain the rapid pace of urbanisation, Hanoi water and sanitation networks are leading to anguish over constant shortcomings, which have generated ingenious and localised alternative systems. Those alternative systems engage citizens at different scales in the production and management of the technical infrastructure for the delivery of water and sanitation services. This engagement involves economic resources (co-funding), maintenance and repair (co-management) and planning (co-planning). 
They do not develop against a lack of centralised water and sanitation networks. On the contrary, they coexist and dialogue with existing infrastructure networks (Rao 2015).

This article considers three neighbourhoods where current co-production of water and sanitation services developed and transformed over time, rather than being planned in advance. These case studies depict the chronological evolution of Hanoi and they reflect specific visions and models of urbanisation. They represent centrally planned urban types connected to the municipal water and sewerage networks. The planning and construction of the technical infrastructure were included in the initial design of the area and the building systems. However, co-production initiatives evolved as "small acts of design" in line with the processes of urban and infrastructure reconfiguration (Rao 2015, p. 41) and the changing relationships between the actors involved.

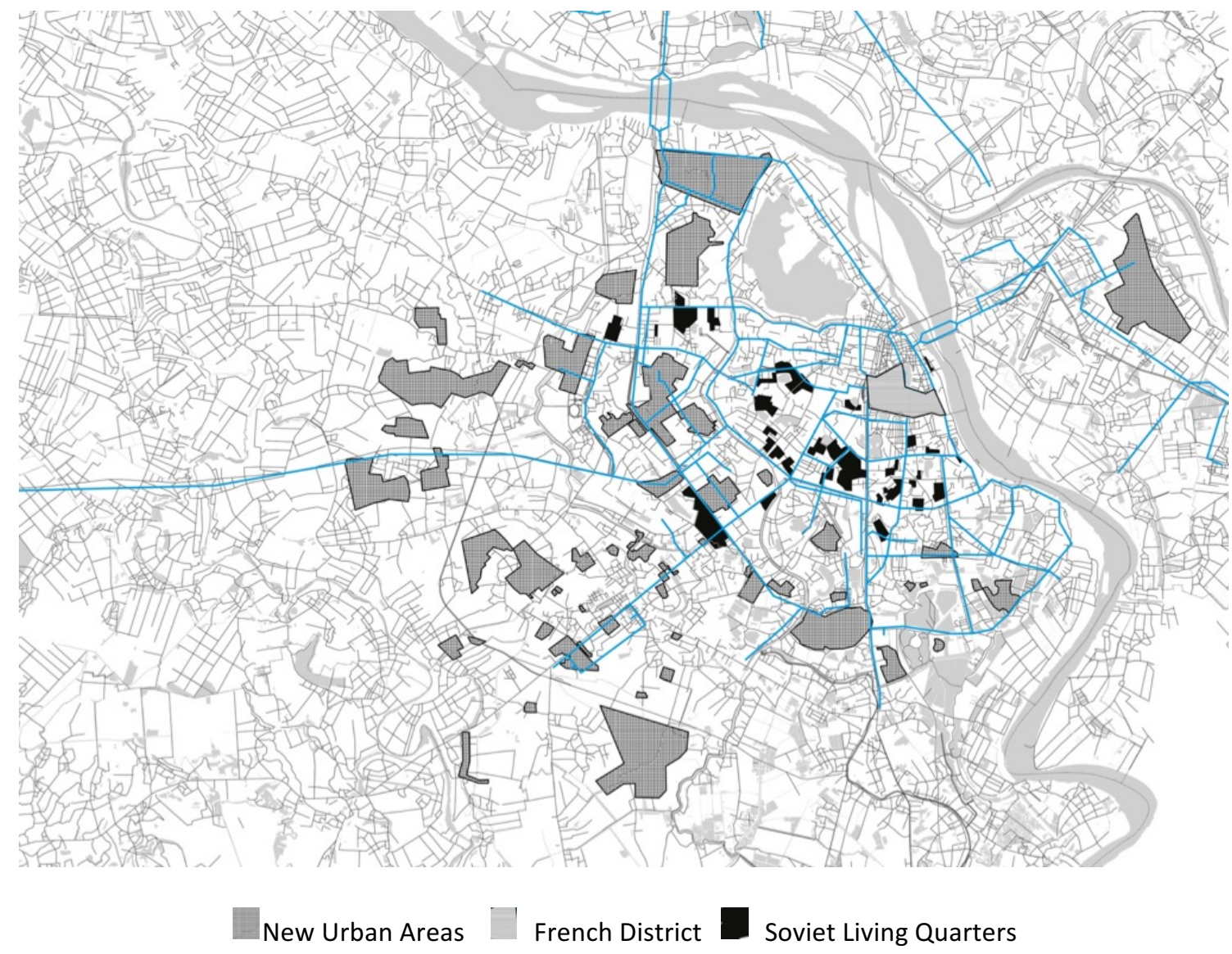

Figure 2. The three models of planned urbanization addressed in Hanoi. French District, KTT Soviet Living Quarters, NUAs New Urban Areas. Image produced by the authors.

\subsection{Reconfiguring the urban block: alleyway households co-producing water}




\section{and sanitation services in the French District}

The French colonial masterplans contained the first phase of formally planned urbanism in Hanoi. The plans were implemented from the 1890 s to the $1940 \mathrm{~s}$ as the first spatial reordering of the traditional urban fabric to accommodate the colonial elite while building the image of a new sanitary capital. The French District predominately covers the southern areas of the Hoàn Kiếm lake. It is organised as a series of isolated and grouped villas surrounded by gardens. During colonial times, the area was connected to the water distribution network and a separate sewerage and drainage system. French engineers included co-production arrangements in the initial design of the technical infrastructure. Indeed, the septic tanks and on-site treatment technologies were first planned and installed in each plot in this area. The flat terrain and the low, dense morphology of the district was characterised by villas, originally inhabited by one or two households and allowed to operate with septic tanks (Schramm and Contreras 2017). According to the French planners, septic tanks required large spaces to operate effectively, as they should be easily accessible. Requiring constant maintenance and periodic cleaning, this technology also required adequate hygiene.

The redevelopment of this area dates to the time of collectivisation (the socialist time), when the Vietnamese Government confiscated and redistributed the colonial plots and houses, either for public functions or to house the families of public officials (Cerise 2009). The progressive development (Turner and Fichter 1972) of the French District consisted of a shifting of territories generated by newly built dweller-driven housing units (Habraken and Teicher 1998). These so-called tube houses (referring to the shape of the houses: tall and very narrow) occupied open spaces that were once the private gardens of colonial villas. As a result of this densification, promoted by the government through a land reallocation plan, urban blocks were reconfigured around narrow alleys overlooked by the entrances of new housing units and around the old colonial villas. 


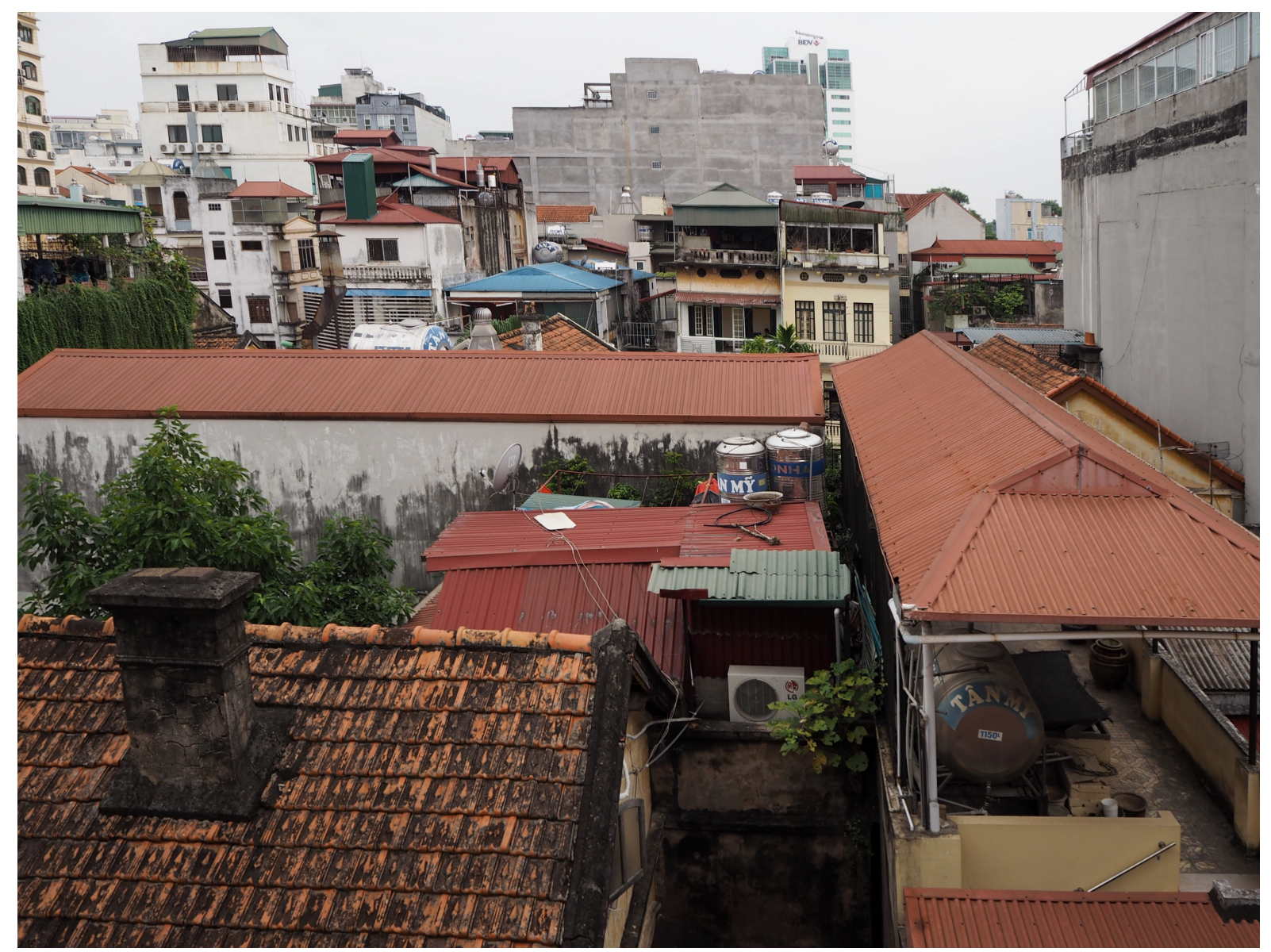

Figure 3: A French villa surrounded by tube houses in Hoan Kiem District (photo by the authors)

Water and sanitation infrastructures progressively expanded with the multiplication of technical devices and the creation of new branches for both water distribution and wastewater collection to supply the new buildings. Regarding the sanitation facilities, each house on the new allotment was provided with a septic tank connected to the combined drainage system. To reduce the amount of wastewater flowing into the tanks, they now only receive blackwater, while stormwater and greywater flow directly into the drainage system (Schramm 2016a). The distribution of control over the sanitation infrastructure occurs at three levels within the area. The management of the primary and secondary lines of the drainage system is the responsibility of the Hanoi Sewerage and Drainage Company, Limited. In the alleys, within the blocks, control over the tertiary drainage lines is in the hands of service users, operating through institutionalised resident groups: tổ dân phố (TDPs). TDPs are responsible for the territorial control of the alleys, narrow streets from 1 to $2.5 \mathrm{~m}$ width, 
inherited from the road networks of ancient villages and defined by formal groupings of continuous rows of houses sharing common spaces (Koh 2006).

Each group is represented by a leader (tổ trương tổ dân phố) elected to represent the community and to mediate with the ward's authorities. As the smallest branches of the Vietnamese political system, resident groups allow the government to maintain a widespread control over the territory. At the same time, as self-regulating institutions, they guarantee to the alleyway households a certain autonomy in the management of water infrastructures and public spaces. Through a common fund, made up of contributions from each household, the TDPs co-plan, co-fund and co-manage the alleyway space at group level (i.e. they improve shared space such as street paving and green areas), allowing the evolution and maintenance of technical services (such as the drainage system). Finally, at the scale of the plot, each household is responsible for the maintenance of the septic tank and the pipes connected to the drainage system.

The distribution of control over the water infrastructure occurs at two levels within the area. The state-owned water enterprise, HAWACO, is responsible for distributing water up to the water meter in front of each house. At the scale of the plot, from the meter on, households are responsible for the construction and maintenance of the water pipes and any other devices necessary to ensure regular flows. To address gaps in service delivery (i.e. low pressure in the pipes that does not allow the water to reach upper floors, as well as an often irregular and dirty water flow), households complement the centralised network. They ensure a constant supply of water by equipping their houses with water storage tanks (both underground for storage and elevated to distribute water by gravity), booster pumps, filter columns and other devices to ensure uninterrupted water flow at sufficient pressure and to improve drinking water quality. Other adjustments in the water network occur in highly dense alleys where plots have been subdivided or parts of houses have been rented. In these cases, several households, working with plumbers, configure a split water supply and share the devices they need to access water services.

The case of the French District shows that an increase of the built environment density triggered the co-production of sanitation services that progressively extend from the scale of the plot (household level) to the scale of the alley (group level), with on-site facilities (collection) under the control of households and tertiary branches (disposal) under the control of TDPs. In this case, co-production initiatives developed as additive practices, since the government, by institutionalising previously informal resident groups (TDPs), recognised them as service providers. Co-production operates here in the last phases of the water cycle (storage and secondary treatment) at the scale of the plot. 
This reveals the stop-gap nature of these co-produced practices of water supply, in which costs are shared among the households and the water company, which keeps control over the branches up to the plot.

\subsection{Re-configuring the socialist condominium: what remains of the collective water infrastructures in the Nguyễn Công Trứ soviet living quarter}

The second phase of significant redevelopments and masterplans dates from the Soviet period. Between 1954 and 1975, the state played an important role in the provision of housing and basic services by providing collective flats (khu tập thể, KTT) to sustain rural-urban migrations and the reconstruction of the country's economy.

The case of Nguyễn Công Trứ represents the first generation of living quarters produced by the Ministry of Construction after the Vietnam War. The neighbourhood, originally a village settlement, is in a historical area of Hanoi, which was converted into a cemetery during the colonial period. In 1960, after the end of colonial domination and during the Soviet period, the French cemetery was removed to construct social housing. According to the original and centrally planned design, khu tập thể Nguyễn Công Trứ consists of 14 housing blocks with four floors each, arranged on three allotments divided by main roads. The presence of public buildings, a general market, a primary school, and a kindergarten reflects the socialist way of producing residential areas at the time. Housing was considered a new social good, and the notion of habitat was associated with collectivism (Cerise 2009). The original flats $\left(30 \mathrm{~m}^{2}\right)$ on each floor were organised around two common spaces. Every floor contained a kitchen and toilets, accessible from a distribution space and shared among eight households. When these large-scale developments were first installed, the state provided for the water and sanitation infrastructure and it covered maintenance costs. The state also discouraged private housing and modification of the built environment through strict controls.

Forms of incremental development in this area started in the 1970s, with the loosening of the management of collective housing by the state. In this context, the collective housing blocks in Nguyễn Công Trứ started to densify mainly through the occupation of public spaces between the blocks and extensions of the flats, the so called tiger cages (chuồng copp). (Cerise 2009; Fanchette 2016). These extended rooms, variable in size and function, are generally supported by steel structures stretching out up to 3 meters from the original façade of the building. A survey conducted in 2007 by Hanoi Housing Development Company No. 7 revealed that the population was then twice the initial population. Several authors reported the different bargaining strategies 
through which residents have ensured a better use of space through illegal construction (Koh 2006; Geertman and Kim 2019). These strategies, which include bribing ward officials, political connections with ward or higher state officers and relying on moral norms and customary rules, often see the head of the local TDP as central in promoting mediation between groups of residents and local authorities (Geertman and Kim 2019).

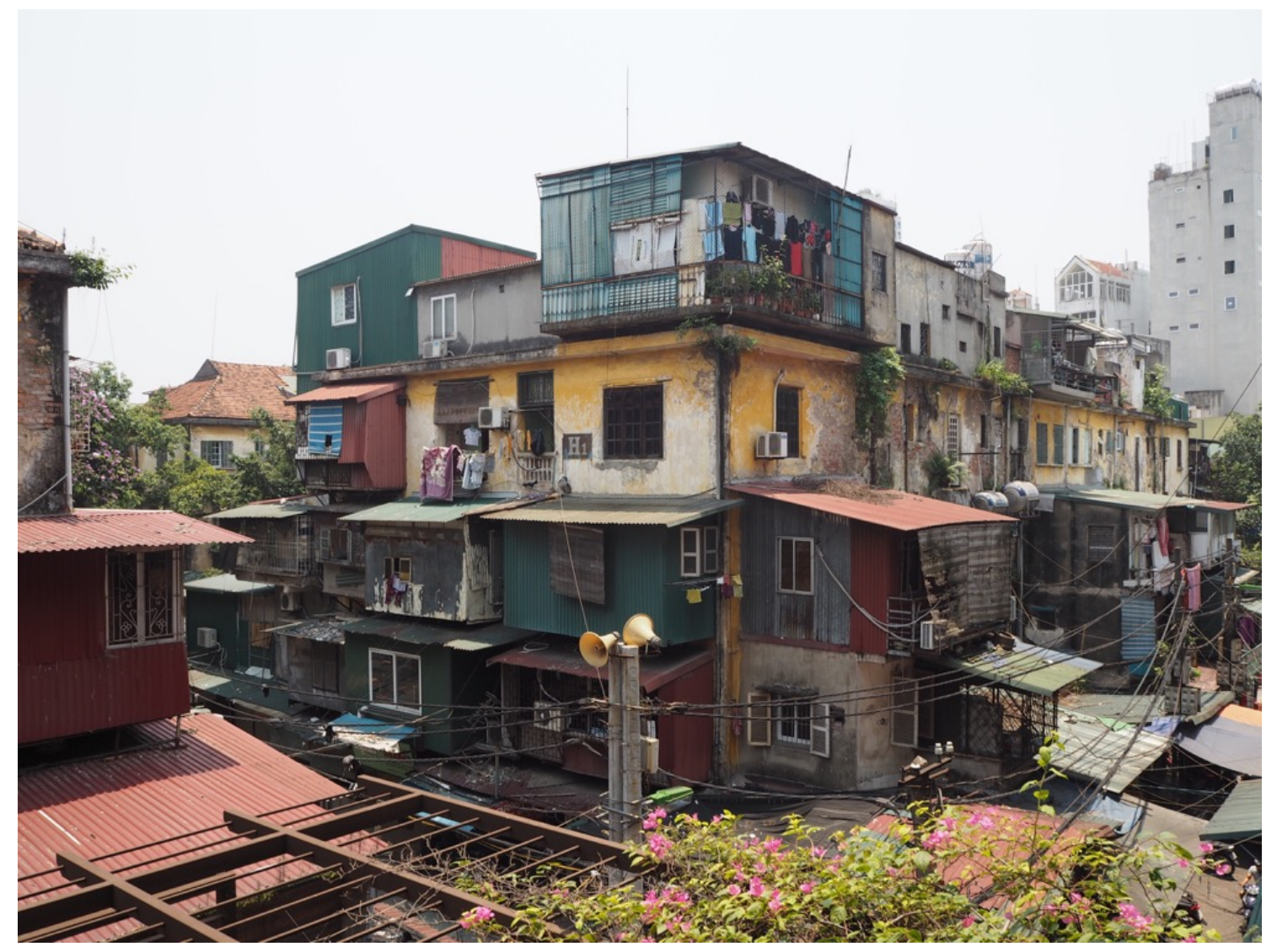

Figure 4: Nguyen Cong Tru original block with extensions (photo by the authors)

As a result of these incremental transformations, the water and sanitation infrastructures have undergone changes that have altered the original configuration. Regarding the water supply system, from the neighbourhood's inception to 1986, the government provided water. Each family had to pay a monthly fixed fee, regardless of its consumption. Water was collected in two main water reservoirs in the neighbourhood and pumped to each block. It was stored in tanks on the rooftops. Water was then distributed by gravity through two main pipes to the common kitchen and toilet areas on each floor. As reported by residents at the time, water was generally available, and some redistribution practices were observed. 
As also observed in other living quarters in Hanoi, co-production initiatives materialised as substitutive practices, since the government progressively retreated from its role as exclusive service provider. The low rental rates (set below the level of actual housing costs) impeded the state housing agencies from collecting sufficient funds for repair and maintenance of the existing housing stock (Nguyen Quang and Kammeir 2002). Residents regularly faced inadequate water pressure, a choked drainage system and poor septic tank maintenance. Moreover, the living conditions in the blocks were unbearable, given the small size of the living space, which was often only $2 \mathrm{~m}^{2}$ per person (Cerise 2009).

To address these deficiencies, Hanoi city administration developed a model of state-private cooperation for the upgrade of these collective areas in the 1980s. This model, known as house repair cooperative schemes (Koh 2006), invited modification of the housing blocks. The government was responsible for selling material and contributing economic support, while residents contributed money and labour. Works included repainting the facades, upgrades of the pipes and building individual kitchens and toilets. Collective spaces were subdivided to install individual/private facilities. The water infrastructure was extended with new branches, each directly connected to the original main pipe. Consequently, the collective water infrastructure (tanks located on the rooftops of each building and pipes) stopped functioning.

Today, each household has at least one private tank to store water (generally anchored to the facade with temporary hanging steel structures) and pays for water according to its consumption. Residents on higher floors often suffer from water shortages, especially in the dry season, when dwellers at the lower floors store too much water. Given the obsolescence of the pipes and the overall infrastructure, many inhabitants employ filters to treat the drinking water. In the French District, the water company controls the branches until the water meter, while households are responsible for the installation and maintenance of small-scale technologies such as water tanks and filter columns in the building blocks.

The control of the sanitation infrastructure is mainly shared by the Hanoi Sewerage and Drainage Company and resident groups. The division of responsibility between these organised groups and the government is unclear. While individual housing units in KTT were privatised in 1994, the common areas remained under government ownership. Thus, the government is officially responsible for maintaining common areas, building structure and common facilities such as sewerage, septic tanks and water storage tanks. In practice, the TDP, through households' contributions, is mainly responsible for the maintenance of drainage and septic tanks and the 
management of waste and common areas. The shared septic tanks and the secondary drainage branches running and collecting overflow from the septic tanks between the blocks are also under the control of residents' groups (TDPs). If in the French district the boundaries of co-production of the sanitary network and public space are defined by the alley, in Soviet living neighbourhoods they are generally defined by two facing blocks.

\subsection{Emerging forms of co-production: from private to community management of water and sanitation infrastructure in Linh Dam towers}

From 1993 to 2001, 80\% of the housing production in Hanoi was in the popular sector, namely housing built spontaneously by individuals within the boundaries of the abovementioned housing policies. In the 2000s, the housing-service scheme promoted by "The State and the People work together" greatly reduced the role of state planning authorities. The revision of the land law in the 2000s marked the beginning of a new phase of urban development. The rise of foreign and state investments supported the production of large, multi-storey buildings and road infrastructures. The current form of urban reordering consists of constructing new urban areas (NUAs) by converting rural land into urbanised land. This conversion occurs through large expropriations of agricultural land, the filling of existing lakes and ponds, and the construction of new high-density built-up areas disconnected from the existing built environment. The majority of the NUAs are produced by domestic companies with strong connections to the state (Tran 2015). By law, the new property complexes must design, integrate and install decentralised infrastructures for water and sanitation. Through this arrangement, called land for infrastructure, planning authorities use the land as an in-kind payment for the construction of technical infrastructure and public services (Labbé and Musil 2014). This phenomenon is contributing to the acceleration in the production of new housing while extending the infrastructure network to peri-urban areas. However, as several authors have shown, investors often try to increase built-up density and surface to gain more profit, neglecting the requirements for public spaces, green areas and facilities (Hien 2005; Tran 2015). 


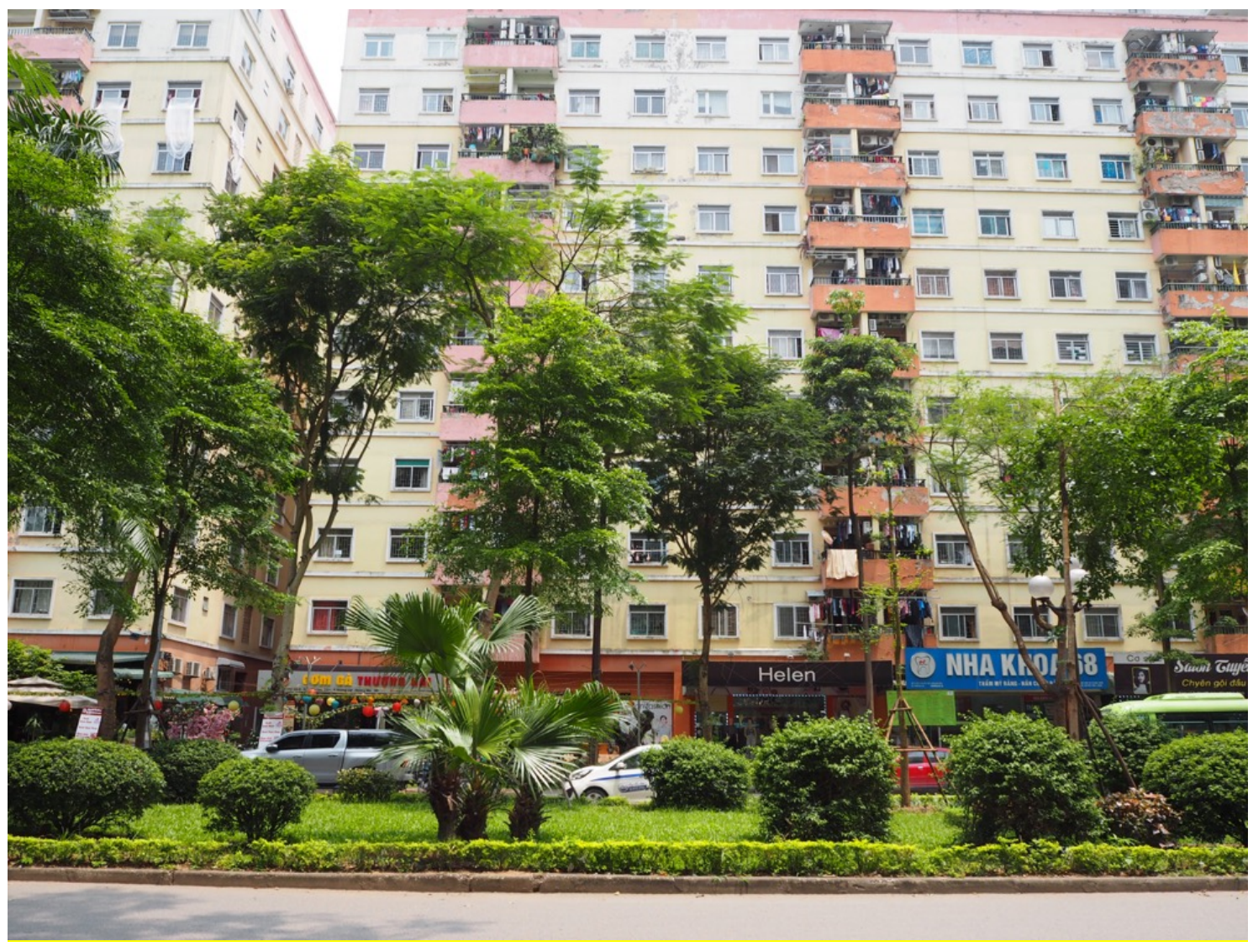

Figure 5: Linh Dam Condominiums (photo by the author)

Linh Đàm was the first NUA project in Vietnam. Strategically located near downtown Hanoi and connected to major transport axes, Linh Đàm was built on former paddy fields. The Urban and Housing Development Investment Corporation (HUD) developed the area after the masterplan was approved in 1999. HUD is a state-owned enterprise operating under the Ministry of Construction. While the planning of the area was centralised, the flats' design and construction were delegated to several subcontractors, who completed the project in 2002. In terms of built environment, Linh Dam appears as a patchwork of Western building types (high-rise buildings), villas, housing blocks, and facilities planned for the upper-middle-class residents.

The overlap of two alternative systems of water supply, developed in two different periods, reflects the increased density in the area. The first system is an independent water supply network that makes use of groundwater captured by ten wells controlled by the Linh Dam Water Company. The second system was implemented in 2017 in response to the constant shortages due to the construction of new tower blocks in the area. This was possible since the investor, to increase profits, took advantage of the presence of a nearby city park. Instead of providing facilities and open areas for the 
residents (parks and playgrounds), it changed the land use of open areas to building land. In 2015, four more 29-32 storey buildings (VP2-VP3-VP4-VP5) were built in this neighbourhood. This process of densification was not foreseen in the original HUD plan. Consequently, the existing water network did not have enough capacity, in terms of either quantity of resources or water pipe sizing. This situation created huge problems with water shortages, as the underground water tanks in the older blocks were no longer receiving sufficient water at adequate pressure. As a result of two years of organised waves of protests and claims with the local People's Committee, new pipelines were built to serve the new buildings. The area started to receive surface water from the $\mathrm{Da}$ River Company No. 4. In each block, the water is first stored in two underground water tanks and afterwards pumped to two water tanks on the upper floor. By gravity feed, it is then distributed to each flat.

The management and maintenance of the technical infrastructure in Linh Đàm, as in other NUAs, is delegated to management boards whose duties, organisation and responsibilities are defined by the 2014 Housing Law.

During the construction phase and the first years of the life of the buildings, the investor nominates a management board to develop and manage the infrastructure in the whole area. When all the flats are sold, the investor is no longer responsible for the maintenance of the technical infrastructure, which is handed over user groups, the residents' management boards, which represent the dwellers in each tower. Unlike resident groups (TDPs), which are an extended arm of the government, management boards only have technical responsibility. They are voted for by the people every 3-5 years, and they play a relevant role in representing the users, negotiating with the property developer and the local authorities, and managing the fees for the maintenance of the buildings and related infrastructure. As Hien (2005) pointed out, the investors often delay the establishment of residents' management boards to maintain control over public space and to increase their profits through its privatization (i.e. property densification, rent). In Linh Đàm, after waves of complaints, these residents' organisations succeeded in forcing private investors to build green areas and playgrounds as opposed to a private gym and a tennis court (Tran 2015).

The co-production between service users and regular providers in NUAs is substitutive, since it is the output of a synergic relationship between planning authorities and the private sector to accelerate the process of urbanisation and service delivery. On the one hand, citizens of NUAs are expected to bear more responsibility and risks related to the high costs of maintaining such large-scale infrastructures. In return, coproduction guarantees them greater decision-making capacity in the allocation of 
resources, lower costs of repair and maintenance and, at the same time, a certain degree of territorial control.

\section{Discussion}

In the case studies addressed in this paper, the different practices of service coproduction have not been planned by policy or designed as such, but they have developed over the time in a co-evolutionary relationship with the built environment and its governing organizations. As a result of constant spatial adjustments, incremental infrastructures and hybrid forms of water and sanitation service provision have emerged and evolved over time, thus inviting some reflections on the incremental nature of service co-production.

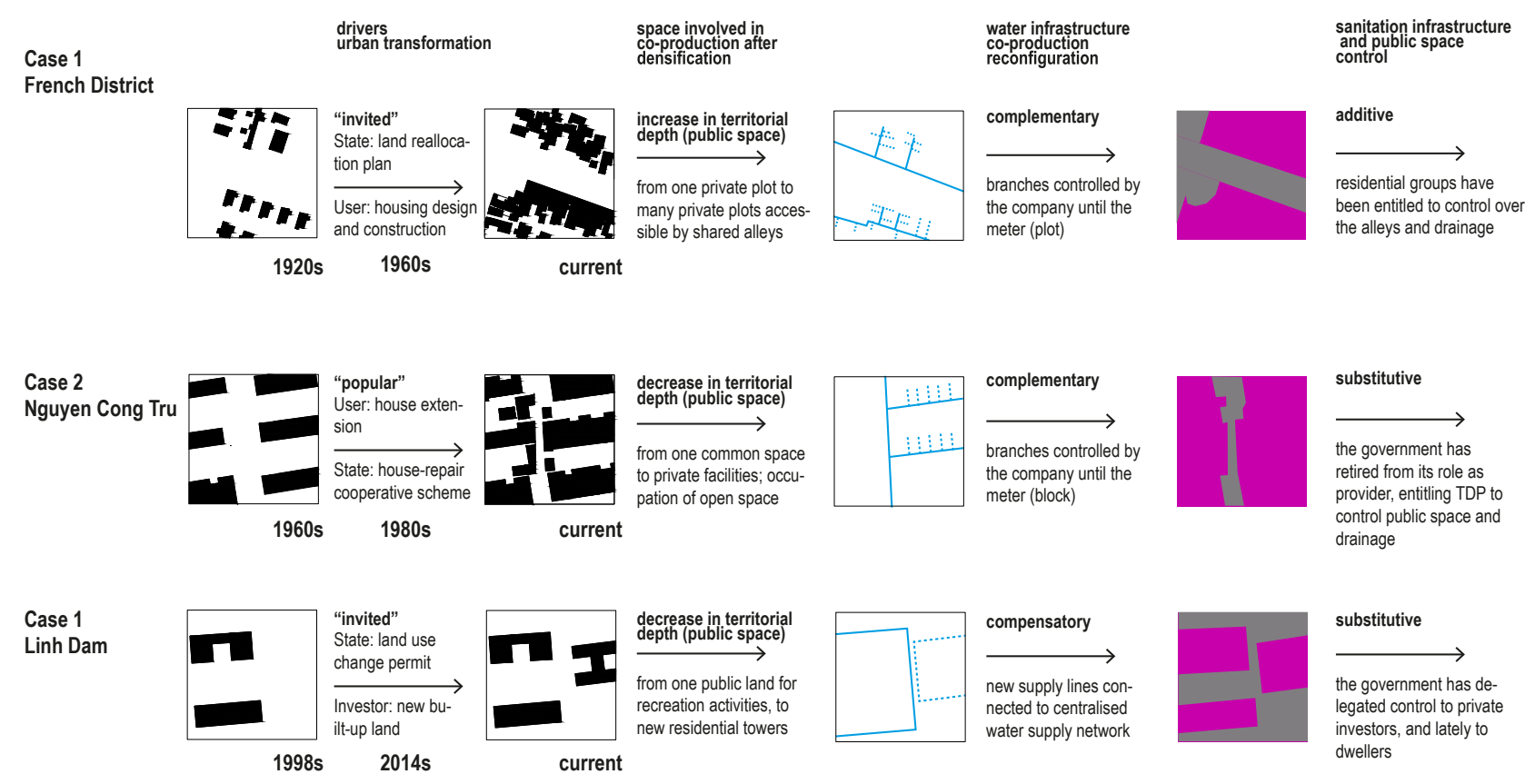

Figure 6. Co-production development in the three case studies. Image produced by the authors.

\section{Shifting territorial boundaries in spaces of co-production}

Technological change and innovation impact the reconfiguration of the urban form and the interactions among urban activities and dwellers (Brotchie 1984). At the same time, the evolution of the city plays a relevant role in the reconfiguration of technologies and their adaptation to social and material needs (Bolay and Kern 2011). 
What emerges from a transversal reading of the three case studies is that the space of co-production is not static but fluid, that is, capable of expanding and contracting from a technological (infrastructure) and managerial (service) point of view. These cases demonstrate a close relationship between the shifting territorial boundaries within the built environment and the functioning and reconfiguring of the technical infrastructures that deliver water and sanitation services.

Three modes of urban incrementalism can be observed. These refer to Dovey and King's (2011) types of settlement growth. The first is inserting buildings into inhabited areas, as shown by the rise of tube houses in the open spaces of colonial villas. The densification of the urban landscape, invited by the state through a land reallocation policy and designed by households, has increased territorial depth through the creation of alleys between the building blocks. This has in turn extended the water and sanitation infrastructure through the multiplication of households' technical devices (tanks) and branches (pipes and lines) connected to a newly built secondary drainage and water pipe.

The second type of densification is attaching, such as the informal accretions that grow out of the Nguyễn Công Trứ building blocks. In this case, common spaces have progressively been turned into private spaces. Unlike the previous case, the water infrastructure expanded through the multiplication of branches directly connected to the original main trunk.

The third model of urban densification is settling on unbounded land. This is the case for the Linh Đàm NUA built by the property investor on the land planned for a park. In this case, the incrementalism of the water and sanitation infrastructure is expressed in the design of a concurrent water supply network, independent of the existing one.

These cases have further helped us to identify two main types of urban and technical incrementalism: a gradual and incremental change and a rapid and discontinuous one (Levinthal 1998). In the first category, we find the step-by-step urban redevelopment triggered by the informal, individual-led extensions in the Soviet blocks and the government-led process of densification of the French District. Both processes of urban transformation through densification have been taken multiple years, triggering a progressive adaptation of the building systems and the technical infrastructure. However, the two case studies differ. In the French District, the reconfiguration of the water and sanitation networks has a cumulative character, as it is the outcome of a series of small-scale, incremental additions over time (Geels 2002). In Nguyễn Công Trứ, the reconfiguration of the water and sanitation infrastructure has a disruptive character, as 
the switch from collective to individual facilities has partially dismantled the original model of service delivery.

In the second category, we find the construction of the new towers by property investors in Linh Đàm. This sudden process of densification challenged the capacity of the existing infrastructure system to cope with incremental changes (increasing amounts of water requested by new dwellers and underestimating water pipe sections). This in turn triggered a redesign of the technical infrastructure, now based on the coexistence of two systems for the water supply.

\section{Complementary versus concurrent co-production}

The literature has shown that technologies mobilised in co-production can contribute to the amelioration of the current conventional system, or they can introduce a further level of complexity into the network (Allen et al. 2017; Jaglin 2012; Moretto and Ranzato 2017). Despite the divergences, the three cases show that technical hybridisation of the water and sanitation infrastructures leads to a co-existence of operational networks, where large-scale centralised infrastructure systems and small-scale decentralised technologies are employed simultaneously to deliver services to urban dwellers.

In the first case, co-production arrangements can result in complementary networks that citizens, beyond the centralised infrastructure, adopt to improve access to water supply and sanitation. In this sense, these self-help initiatives reconfigure and complete unfinished networks through the means of alternative, small-scale sociotechnical arrangements installed and managed by households (Zérah 2000). This model applies to both the tube houses in the French District and the Soviet blocks in Nguyễn Công Trứ, where the smaller networks at the level of the house and block develop to correct gaps in service delivery (i.e. low pressure in the pipes, which does not allow the water to reach upper floors, as well as an often irregular and dirty water supply). Since, the densification processes in the Soviet neighbourhood and the French District were not sustained by adequate public infrastructure, co-production materialised in complementary strategies that allowed the public network to reach the last built-up units. Those compensatory strategies represent what Kyessi (2005), referring to the technological upgrade of water infrastructure in Dar Es Salam, would define as a "stepby-step" development model (p. 10). The devices installed depend mainly on the financial capacity of the household, as well as the characteristics of the settlement where they are to be installed. These devices coexist with large-scale technical infrastructures, as in the case of Linh Đàm, where, despite the employment of high-tech and large-scale 
solutions, groundwater contamination by arsenic forced households to equip their flats with water filters, or to buy bottled water.

Technical hybridisation can also occur at larger scales, such as at the scale of the neighbourhood, and it can result in the coexistence of concurrent networks. In Linh Đàm, the existence of two water networks can be explained by the increasing contamination of underground water and the overpopulation of the area, which was not foreseen in the initial design. In this case, the infrastructure system has developed mainly from a decentralised solution (wells connected to an independent network) to a more centralised (subnetwork) model. The expansion of the technical portfolio, due to the differentiation of water resources (from groundwater to both groundwater and surface water), should be understood as a wider program at the municipal level. The plan is to increase the use of surface water, mainly due to the decline of the groundwater level and the increasing contamination of arsenic, coliforms and nitrogen (Bui et al. 2018), and to extend the networked infrastructure to those areas (mainly peri-urban) which are still disconnected.

As we have seen, incrementalism contributes to producing more complex networks through different types of technical infrastructure. This incremental development allows us to navigate from more formal to more informal ways of service provision and vice versa (Misra 2014), producing an assemblage of centralised and decentralised technical solutions, which characterise the hybrid nature of service coproduction.

\section{The cyclical nature of service co-production}

The existing literature presents co-production as a linear process, and it tends to differentiate types of co-production according to the phase of the service cycle in which citizens are engaged (Moretto and Ranzato 2017). Co-production is generally disaggregated into co-planning, co-design, co-delivery, and co-assessment, referring to the stage within the service cycle in which community and state actors work together to produce something of value (Nabatchi et al. 2017).

However, the technological incrementalism highlighted in the three cases analysed in this paper questions a linear understanding of co-production. The analysis instead suggests a cyclical model of technological change, where periods of incremental change in the water and sanitation infrastructure are disrupted by subsequent technological breakthroughs (Anderson and Tushman 1990; Geels 2002).

Incrementalism implies a feedback loop of disruption and redesign of the technical 
infrastructure, which feeds co-production activities, as citizens are permanently engaged in fixing, disrupting and redesigning their built environment and embedded infrastructure systems.

On the one hand, co-production and technical incrementalism represent strategies to fix disruption. Indeed, the co-produced arrangements that emerge in the presented cases can be considered as sociotechnical solutions that address the shortcomings of existing infrastructure systems (water shortages, irregular pressure, unsafe quality, or clogs of sewerage pipes) during a transitory phase. The material reconfiguration of the analysed co-produced infrastructures largely relies on hybrid and/or decentralised systems able to replace or complement the infrastructure network.

On the other hand, co-production and incrementalism are also provoking disruption, as the growth of the settlement can threaten the good functioning and proper maintenance of current sanitation infrastructures up to the point where the infrastructure collapses. The more complex an infrastructure system becomes, the more severe the issues of maintenance, technical breakages and shortages that users and/or providers need to face. As the case of the Soviet blocks in Nguyễn Công Trứ shows, despite a regular, centrally controlled water flow in each block, households continuously need to address inequalities in the way they access water services. When the tenants of the lower floors store too much water (by buying tanks of greater capacity or providing their units with more than one tank), the tenants of the upper floors suffer from water shortages.

In addressing and at the same time feeding disruption, co-production implies that citizens constantly redefine their spatial conditions and redesign the technical portfolio they employ. In this sense, we understand that the co-production of water and sanitation services is a self-feeding process which, by nature, through breakages and adaptations, produces innovation and further transformations. "Indeed, there is some evidence to suggest that this kind of piece-by-piece adaptation is a leading cause of innovation, acting a continuous feedback loop of experimentation, which, through many small increments in practical knowledge, can produce large changes" (Graham and Thrift 2007, p. 5).

\section{Technological incrementalism and co-production at different scales}

The literature tends to differentiate co-production according to the scale of user involvement in the service delivery process. Users can be engaged in co-production of service delivery as individuals, groups or collectives (Brudney and England 1983), and they can operate within different territorial boundaries, i.e. at the scale of the house, the 
street, or the neighbourhood (Moretto et al. 2018; Faldi et al. 2019). On one hand, this affects the distribution of benefits (users are more incentivised to co-produce where the benefits are personal) and, on the other, it affects the organisational and management aspects of the co-produced service. Van Vliet et al. (2005) suggested that the size of an organisation depends on the scale of the technology. Larger system scales may imply more complex technical devices, and consequent changes in roles of users and their scale of involvement might lead to a change in service co-production schemes.

The building systems of the three case studies differ in terms of housing type as well as scale, ranging from individual 4-storey dwellings (the tube houses between the French colonial villas), 4-storey collective blocks (Nguyễn Công Trứ socialist housing) and 30-storey blocks of flats (Linh Đàm NUA). As we have seen, co-production does not develop in the same way in different built environments. The related technical infrastructure and devices employed vary with the scale of buildings. Available technology for co-production depends on contextual features, such as settlement characteristics, land location, and distance and/or connection to the centralised networks (Moretto et al. 2018). Density and housing typologies should also be considered determinants of water and sanitation co-production, as they influence the technological systems and devices that can be employed (Schramm 2011).

Hierarchical structures, such as water supply networks, can be considered as assemblies, composed of different parts "that lend themselves for control by separate agents in charge of the design or maintenance" (Habraken 1987, p. 3). The urban morphology (plot, street, constructed space, open space) shapes the typologies and control over water and sanitation service infrastructures, and it defines the opportunities and constraints of incremental development. As we have seen in the high-density French District, the size of the alleys shapes the boundaries of the group co-production in the management of the tertiary drainage system, as well as limiting the possibilities of further incremental development. At the same time, the size of the dwellings (mainly inhabited by one household) and the dwellings' vertical growth triggers household coproduction practices, such as the installation and maintenance of septic tanks, water pumps and storage tanks. In Nguyễn Công Trứ, the original design of the buildings and the open space between blocks represented an opportunity for individual households to extend their private space, while installing individual facilities (kitchen and toilets). This situation, in turn, contributed to the switch from a group level of co-production of water supply (which is still operating for the sanitary network) to an individual one, through the multiplication of small-scale technologies that are easily installed in the blocks and suitable to the building's height. 
Incrementalism describes the spontaneous room-by-room process of accretion of the built environment that extends the building systems horizontally (i.e. in the building blocks in Nguyễn Công Trứ) or vertically (in the French district tube houses). This process, driven by the imperatives of resource accumulation, family ties and spatial conditions is more likely to occur on small-scale plots (such as the tube houses), as they allow many people to engage directly in designing, building and maintaining their built environment (Brandt 1994). However, it seems that co-production has transformed more consistently on the intermediate scale of Nguyễn Công Trứ, as the scale of the buildings and the public space organised between the built-up areas has allowed both vertical and horizontal expansions of the built space and the overall redesign of the technical infrastructure employed.

In large-scale property developments, this process of adaptation is not likely to develop in the same way, and the upgrade of water infrastructures might be more problematic and costly. In the NUA of Linh Đàm, the difficulties in maintaining the large-scale technical infrastructure are reflected in the complex system of operation of the management boards, which have to coordinate many actors, and to organise among the different towers. At present, this built environment does not seem adequate for urban incrementalism, as the building codes strictly forbid any private transformation. However, all buildings are prone to change with time. A process of infringement is already occurring, as households are starting to set up shops and workplaces in their homes and customising the building's ground floors to host activities and services for the neighbourhood. This may in future expand the existing water and sanitation infrastructure.

\section{Conclusions}

The relationship between planned built environments and incremental spatial transformations has been discussed in three case studies through examples of different urban, social and political visions that the city of Hanoi has embedded over the years. In these case studies, incrementalism has been produced and scaled through material reconfigurations that experimented with new forms of sociotechnical infrastructure due to changes in spatial patterns (Silver 2014).

In conclusion: first, the three cases have highlighted a relationship between the evolution of co-production practices that deliver the water and sanitation services and the changing control of state and community actors in the production and maintenance of the built environment. In particular, they have highlighted the role of community 
organisations (TDPs and residents' management boards) as central in reworking the state's boundaries (Koh 2006). This confirms the fluid nature of Vietnamese urbanisation processes, where popular, bottom-up impulses are incrementally accommodated within state-led dynamics of space production (Koh 2006; McGee 2009; Tran 2015).

Second, the empirical evidence presented in this article confirms that infrastructures play a central role in the incremental process of consolidation and reconfiguration of the built environment. Infrastructures' adaptability to changing spatial conditions influence the ways different forms of co-production initiatives develop on different scales to guarantee and/or improve access to water and sanitation services.

Third, most of these incremental transformations trigger urban and technical hybridisation, as the densification of the building systems requires an extension or a multiplication of the technical portfolio in the service cycle. Hybridisation can take the shape of downscaling the key technologies and infrastructures providing water and sanitation services. It can lead to complementary or concurrent forms of co-production, but it can also contribute to the disruption of existing technical systems and their substitution with new ones. As a consequence of those processes, the centralised provision of water and sanitation and localised co-production has become mixed up (van Vliet 2012).

Finally, the cases have shown that such reconfiguration processes are not necessarily rapid. Instead, they are often the outcomes of a series of small, incremental adaptations over time, whose cumulative effect can be at least as substantial as the effect of abrupt innovations (Geels 2002). Both forms of innovation require users to "play an active role in adsorbing, coordinating, and even orchestrating the disruption" (Furlong 2014, p. 143).

However, despite being incremental and provisional, these sociotechnical arrangements can also be progressively replaced by others due to broader urban dynamics and environmental transformations. These factors make it very hard to evaluate the sustainability of co-produced arrangements. Moreover, the risks of sociospatial fragmentation linked with technical and urban incrementalism exist. This issue deserves further empirical and theoretical research. Understanding those trajectories can provide useful insights on the pathways of adaptation that co-production initiatives develop to address changing spatial conditions, and to improve livelihoods and access to urban services. 


\section{References}

Ahlers R, Cleaver F, Rusca M, Schwartz K. 2014. Informal space in the urban waterscape: disaggregation and co-production of water services. Water Alternatives. 7(1): $1-14$.

Aimini M. 2013. Hànôi 2050, Trilogia di un paesaggio Asiatico [Trilogy of an Asian landscape]. Roma: INU Edizioni.

Allen A, Hofmann P, Mukherjee J, Walnycki A. 2017. Water trajectories through nonnetworked infrastructure: insights from peri-urban Dar es Salaam, Cochabamba and Kolkata. Urban Res \& Pract. 10(1): 22-42.

Anderson P, Tushman ML. 1990. Technological discontinuities and dominant designs: a cyclical model of technological change. Adm Sci Q. 35: 604-633.

Bolay J-C, Kern A. 2011. Technology and cities: what type of development is appropriate for cities of the South? J Urban Technol. 18(3): 25-43.

Bovaird T. 2007. Beyond engagement and participation: user and community coproduction of public services. Public Adm Rev. 67. 846-860.

Bovaird T, Loeffler E. 2012. From engagement to co-production: the contribution of users and communities to outcomes and public value. Voluntas. 23: 1119-1138.

Brandt S. 1994. How buildings learn. What happens after they are built. New York: Viking Penguin.

Brotchie JF. 1984. Technological change and urban form. Environ and Plan A: Econ and Space. 16(5): 583-596.

Brudney J, England R. 1983. Toward a definition of the coproduction concept. Public Adm Rev. 43(1): 59-65.

Bui NT, Kawamura A, Amaguchi H, Bui DD, Truong NT, Nakagawa K. 2018. Social sustainability assessment of groundwater resources: a case study of Hanoi, Vietnam. Ecol Indic. 93:1034-1042.

Button C. 2017. The co-production of a constant water supply in Mumbai middle-class apartments. Urban Research \& Practice. 10(1): 102-119.

Cabrera JE. 2015. Fragmentation urbaine à travers les réseaux techniques [dissertation]. Liège (Belgium): Université de Liège.

Cerise E. 2009. Fabrication de la ville de Hanoi entre planification et pratiques habitantes: conception, production et réception des formes bâties [Manufacture of the city of Hanoi between planning and living practices: design, production and reception of built forms] [dissertation]. Paris: Paris 8 . 
Cornwall A. 2004. Introduction: New democratic spaces? The politics and dynamics of institutionalised participation. IDS Bulletin 35(2): 1-10.

Deleuze G, Guattari F. 1987. A thousand plateaus: capitalism and schizophrenia. Minneapolis (MN): University of Minnesota Press.

Dovey K, King R. 2011. Forms of informality: morphology and visibility of informal settlements. Built Env. 37(1).

Faldi G, Rosati FN, Moretto L \& Teller J. 2019. A comprehensive framework for analyzing co-production of urban water and sanitation services in the Global South. Water Int. 44(8): 886-918.

Fanchette S. 2016. Hà Nội, a metropolis in the making. The breakdown in urban integration of villages. Marseille: IRD Éditions.

Furlong K. 2014. STS beyond the "modern infrastructure ideal": extending theory by engaging with infrastructure challenges in the South. Technol in Soc. 38: 139-147.

Geels FW. 2002. Technological transitions as evolutionary reconfiguration processes: a multi-level perspective and a case-study. Res Policy. 31(8-9): 1257-1274.

Geertman SJL. 2003. Who will build the Vietnamese city in the 21 st century? Globalization and tradition in land and housing in Hanoi. Journal of Comparative Asian Development. 2(1): 169-190.

Geertman SJL. 2007. The self-organizing city in Vietnam: processes of change and transformation in housing in Hanoi [dissertation]. Eindhoven (Netherlands):

Technische Universiteit Eindhoven.

Geertman SJL, Kim B. 2019. A study of informally developed housing and its role in the political arena of a post-reform Communist city. In: Rocco R \& van Ballegooijen J, editors. The Routledge handbook on informal urbanization. New York (NY): Routledge, p. 112-123.

Graham S, Thrift N. 2007. Out of order: understanding repair and maintenance. Theory, Cult \& Soc. 24(3): 1-25.

Habraken NJ. 1987. Control hierarchies in complex artifacts. In: Protzen J-P editor. Proceedings of the 1987 Conference on Planning and Design in Architecture at the International Congress on Planning and Design Theory; Aug 17-20; Boston. Massachusetts. p.1-22.

Habraken NJ, \& Teicher J. 1998. The structure of the ordinary: Form and control in the built environment. Cambridge (MA): MIT Press.

Hien NT. 2005. Report: urban governance in preservation and management of neighborhood parks/playgrounds in inner-city districts of Hanoi. Hanoi: Asia Foundation, HealthBridge. 
Jaglin S. 2002. The right to water versus cost recovery: Participation, urban water supply and the poor in sub-Saharan Africa. Environ Urban. 14(1): 231-245.

Jaglin S. 2012. Networked services and features of African urbanization: other path toward globalization. L'espace Geogr. 41(1): 51-67.

Joshi A, \& Moore M. 2004. Institutionalised co-production: unorthodox public service delivery in challenging environments. J Int Dev. 40(4): 31-49.

Kerkvliet B. 2001. An approach for analysing state-society relations in Vietnam. Sojourn. 16 (2): 238-278.

Kyessi AG. 2005. Community-based urban water management in fringe neighbourhoods: the case of Dar es Salaam, Tanzania. Habitat Int. 29: 1-25.

Koh DWH. 2006. Wards of Hanoi. Singapore: Institute of Southeast Asian Studies.

Labbé D, Musil C. 2014. Periurban land redevelopment in Vietnam under market socialism. Urban Stud. 51(6): 1146-1161.

Levinthal DA. 1998. The slow pace of rapid technological change: gradualism and punctuation in technological change. Industrial and Corporate Change. 7(2): 217-247. McFarlane C. 2011. Learning the city: knowledge and translocal assemblage. Hoboken (NJ): Wiley.

McGee TG. 2009. Interrogating the production of urban space in China and Vietnam under market socialism. Asia Pac Viewp. 50(2): 228-246.

Misra K. 2014. From formal-informal to emergent formalisation: fluidities in the production of urban waterscapes. Water Altern. 7(1): 15-34.

Mitlin, D. 2008. With and beyond the state-co-production as a route to political influence, power and transformation for grassroots organizations. Environ and Urban. 20(2): 339-360.

Monstadt J, Schramm S. 2015. Changing sanitation infrastructure in Hanoi: hybrid topologies and the networked city. In: Coutard O, Rutherford J, editors. Beyond the networked city: infrastructure reconfigurations and urban change in the North and South. 1st ed. London: Routledge; p. 6-50.

Moretto L, Faldi G, Ranzato M, Rosati FN, Ilito Boozi J-P, Teller J. 2018. Challenges of water and sanitation service co-production in the global South. Environ and Urban. 30(2): 425-443.

Moretto L, Ranzato M. 2017. A socio-natural standpoint to understand coproduction of water, energy and waste services. Urban Res \& Pract. 10(1): 1-21.

Nabatchi T, Sancino A, Sicilia M. 2017. Varieties of participation in public services: the who, when, and what of coproduction. Public Admin Rev. 77: 766-776. 
Nguyen Quang V, Kammeir DH. 2002. Changes in the political economy of Vietnam and their impacts on the built environment of Hanoi. Cities. 19(6): 373-388.

Offner J-M. 1993. Le développement des réseaux techniques: un modèle générique. Flux. 13(14): 11-18.

Ostrom E. 1990. Governing the commons: The evolution of institutions for collective action. Cambridge (UK): Cambridge University Press.

Ostrom E. 1996. Crossing the great divide: coproduction, synergy, and development. World Dev. 24(6): 1073-1087.

Rao V. 2015. Infra-city: speculations on flux and history in infrastructure-making. In:

Graham S \& McFarlane C, editors. Infrastructural lives. London: Routledge, p. 39-58 Schramm S. 2011. Semicentralised water supply and treatment: options for the dynamic urban area of Hanoi. Vietnam J of Environ Assess Policy and Manag. 13(2): 285-314. Schramm S. 2014. Stadt im Fluss. Die Abwasserentsorgung Hanois im Lichte sozialer und räumlicher Transformationen [City in the river. The sanitation of Hanoi in the light of social and spatial transformations]. Stuttgart: Franz Steiner.

Schramm S. 2016a. Hanoi's septic tanks - technology of a city in flow in the late nineteenth century and today. In Carola Hein (ed.) International Planning History Society Proceedings, 17th IPHS Conference, History-Urbanism-Resilience, Tu Delft 17-21 July 2016. Delft: IPHS, p. 345.

Schramm S. 2016b. Flooding the sanitary city. City. 20(1): 32-51.

Schramm S, Contreras LW. 2017. Fragmented landscapes of water supply in suburban Hanoi. Habitat Int. 61: 64-74.

Silver J. 2014. Incremental infrastructures: material improvisation and social collaboration across post-colonial Accra. Urban Geogr. 35(6): 788-804.

Tran HA. 2015. Urban space production in transition: the cases of the new urban areas of Hanoi. Urban Pol Res. 33(1): 79-97.

Turner J, Fichter R. 1972. Freedom to build: dweller control of the housing process. New York (NY): Collier-Macmillan.

van Vliet BJM, Chappels H, Shove E. 2005. Infrastructure of consumption:

Environmental innovations in the utility of industries. London: Earthscan. van Vliet BJM. 2012. Sustainable innovation in network-bound systems: implications for the consumption of water, waste water and electricity services. J Environ Policy \& Plan. 14(3): 263-278.

Watson V. 2014. Co-production and collaboration in planning - the difference. Plann Theor Pract. 15(1): 62-76. 
Zérah M-H. 2000. Household strategies for coping with unreliable water supplies: the case of Delhi. Habitat Int. 24(3): 295-307. 